06

\title{
Создание наноструктурированной поверхности кремния методом селективного химического травления
}

\author{
() А.Б. Сагындыков, ${ }^{1}$ Ж.К. Калкозова, ${ }^{2}$ Г.Ш. Яр-Мухамедова, ${ }^{1}$ Х.А. Абдуллин ${ }^{2}$ \\ ${ }^{1}$ Казахский национальный университет им. аль-Фараби, \\ 050000 Алматы, Казахстан \\ ${ }^{2}$ Национальная нанотехнологическая лаборатория открытого типа, \\ Казахский национальный университет им. аль-Фараби, \\ 050040 Алматы, Казахстан \\ e-mail: zh.kalkozova@mail.ru
}

(Поступило в Редакцию 20 февраля 2017 г.)

Методом селективного химического травления, инициированного металлическими нанокластерами, в двухэтапном процессе получены наноструктурированные поверхности кремниевых пластин с низким коэффициентом отражения. На кремниевых подложках, покрытых нанокластерами серебра, эффект усиленного поверхностью рамановского рассеяния наблюдался до концентраций радомина $\sim 10^{-12} \mathrm{M}$. Зависимость глубины наноструктурированного слоя от условий проведения двухэтапного процесса травления, в частности от длительности травления, является весьма слабой при определенных технологических параметрах. При прочих равных условиях проведения процесса травления в кремнии р-типа проводимости скорость образования текстурированного слоя в два раза выше, чем в кремнии $n$-типа.

DOI: 10.21883/JTF.2017.11.45127.2211

\section{Введение}

В области материалов для возобновляемой энергетики активно развивается технология создания наноструктурированного кремния [1]. Поверхность такого кремния имеет текстуру в виде вертикальных наноразмерных колонн, что приводит к многократному отражению и эффективному поглощению падающего на поверхность света. Поэтому можно достичь очень низкого коэффициента отражения света во всем видимом диапазоне, и, что важно для солнечных элементов (СЭ), низкий коэффициент отражения света достигается как при нормальном падении света, так и при наклонном освещении СЭ [2]. Соответственно отпадает необходимость в создании просветляющих покрытий для СЭ. Наноструктурированный кремний имеет высокий коэффициент оптического поглощения, что позволяет использовать тонкие кремниевые пластины для изготовления СЭ, и за счет экономии кремния повышается экономическая эффективность процесса производства СЭ.

В настоящее время СЭ на основе наноструктурированного кремния с конформным покрытием из оксида алюминия для обеспечения химической и электрической пассивации продемонстрировали эффективность выше 22\% [3]. Наноструктурированный кремний имеет также потенциал практического применения для создания на его основе светоизлучающих устройств [4], антибактериальных покрытий [5], газовых датчиков, датчиков на основе эффекта поверхностно-усиленного рамановского рассеяния (SERS) [6]. Поэтому в последнее время активно проводятся исследования методов создания наноструктурированного кремния для СЭ и других приборных структур.
Как известно, слои наноструктурированного кремния можно получить путем травления, инициированного металлическими кластерами, при этом часто применяется двухэтапная химическая обработка пластин [7,8]. Толщина слоя наноструктурированного кремния зависит от времени травления по степенному закону с показателем степени, близким к единице [9]. С другой стороны, при увеличении толщины слоя растет поверхностное сопротивление. Поэтому при формировании слоя наноструктурированного кремния с низким коэффициентом отражения для создания солнечных элементов необходимо получать неглубокие слои с однородной толщиной на большой площади. Критичным является как определение режимов получения слоев с оптимальными характеристиками, так и слабое отклонение свойств слоев от оптимальных при небольших вариациях технологических параметров. В настоящей работе приведены результаты по получению текстурированной поверхности кремния с низким коэффициентом отражения. Разработаны такие режимы формирования слоя, которые обеспечивают весьма слабую зависимость толщины наноструктурированного слоя от параметров процесса, что важно при создании СЭ.

\section{1. Экспериментальная часть}

В качестве исходных подложек использовались полированные пластины кремния с размером $10 \times 20 \mathrm{~cm}$, полупроводникового качества, легированные бором $(p-\mathrm{Si})$ или фосфором $(n-\mathrm{Si})$, с удельным сопротивлением $5-15 \Omega \cdot \mathrm{cm}$. Поверхность кремниевых пластин перед использованием подвергалась очистке кипячением в 
ацетоне и этаноле с последующей обработкой в кипящем водном растворе гидроксида аммония и перекиси водорода, с финишной промывкой в деионизованной воде. Предварительная очистка поверхности исходных кремниевых пластин обеспечивает однородность формирования последующей текстуры. Наноструктурированная поверхность кремния формировалась с помощью двухэтапной химической обработки пластин [7-9].

Для создания диффузионных $p-n$-переходов был изготовлен диффузант на основе изопропилового спирта, соляной кислоты и тетраэтоксисилана. В случае диффузии бора в $n$-Si в гель добавлялась борная кислота $\mathrm{H}_{3} \mathrm{BO}_{3}$, для диффузии фосфора в $p$-Si в гель добавлялась ортофосфорная кислота $\mathrm{H}_{3} \mathrm{PO}_{4}$, при этом соотношение основных и примесных компонентов в геле варьировалось. Гель наносился методом центрифугирования.

Для создания мелких диффузионных $p-n$-переходов применен метод импульсного светового отжига, который проводился при температуре $950-1050^{\circ} \mathrm{C}$ в течение $\sim 20$ s в печи светового отжига. Время нагрева до $950^{\circ} \mathrm{C}$ составляло около $10 \mathrm{~s}$.

Морфология поверхности образцов исследовалась методом сканирующей электронной микроскопии (SEM) на электронном микроскопе Quanta 200i 3D (FEI Company). Спектры оптического отражения измерены на спектрофотометре UV-3600 (Shimadzu), спектры рамановского рассеяния - на микроскопе с системой регистрации рамановского отражения NTEGRA SPECTRA (NT-MDT) при возбуждении синим лазером на длине волны $473 \mathrm{~nm}$. Вольт-амперные характеристики полученных структур в темноте и при освещении галогеновой лампой были измерены с помощью потенциостата Р-30J (Elins). Определение эффективности полученных СЭ проводилось путем измерения темновых и световых вольт-амперных характеристик СЭ и их сравнения с вольт-амперной характеристикой эталонного СЭ с известным значением эффективности.

\section{2. Результаты и их обсуждение}

В ходе двухэтапной процедуры получения наноструктурированной поверхности кремния на первом этапе на поверхности подложки формировались металлические наночастицы серебра, на втором этапе осуществлялось селективное травление поверхности кремниевой пластины, инициированное металлическими нанокластерами.

Первый этап состоял в обработке подложек в водном растворе плавиковой кислоты и соли металла - нитрата серебра $\mathrm{AgNO}_{3}$. При проведении экспериментов использованы растворы $\mathrm{H}_{2} \mathrm{O}: \mathrm{HF}$ с варьируемым соотношением компонентов и концентрациями по $\mathrm{AgNO}_{3}$. Пластины кремния погружались в водный раствор $\mathrm{H}_{2} \mathrm{O}+\mathrm{HF}+\mathrm{AgNO}_{3}$ на время от 10 до $60 \mathrm{~s}$, затем процесс прекращался путем разбавления раствора водой.

Обнаружено, что применение концентрации $\mathrm{AgNO}_{3}$ менее $4 \mathrm{mmol} / 1$ приводило к плохо воспроизводимым ре-

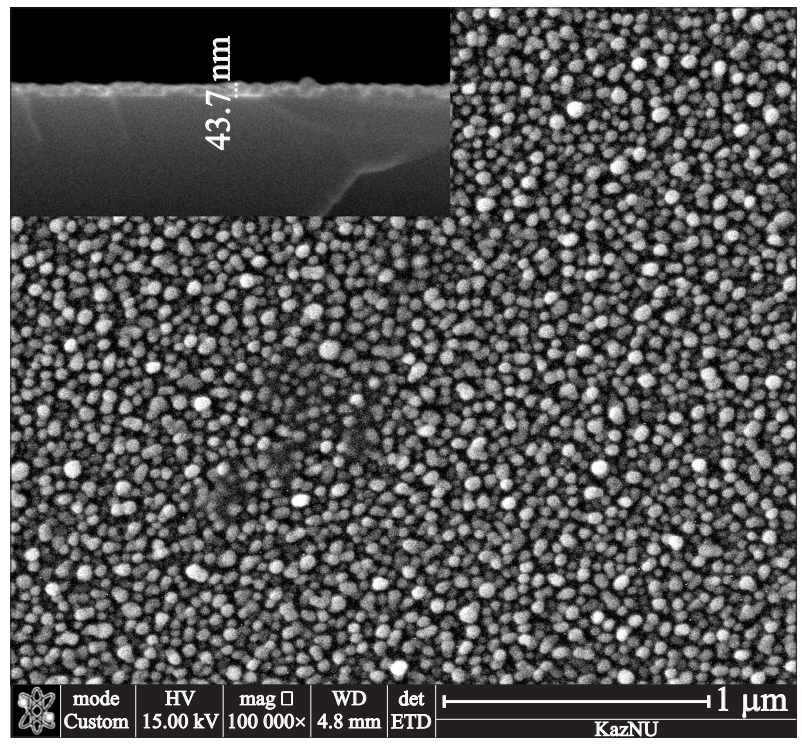

Рис. 1. SЕМ-снимок поверхности и бокового скола кремниевой подложки после первого этапа обработки в $8 \mathrm{mmol} / 1$ растворе $\mathrm{AgNO}_{3}$ в плавиковой кислоте в течение $20 \mathrm{~s}$.

зультатам. При концентрации более $10 \mathrm{mmol} / \mathrm{l}$ толщина слоя получалась слишком большой. На рис. 1 показана морфология поверхности кремния после первого этапа обработки в водном растворе плавиковой кислоты и нитрата серебра. Видно, что на поверхности кремниевой подложки наночастицы расположены в один слой, со средним размером порядка $50 \mathrm{~nm}$. Оптимальная длительность обработки для создания одиночного слоя наночастиц составляла $10-30 \mathrm{~s}$. Элементный микроанализ показал, что частицы состоят из серебра.

Полученные после первого этапа обработки образцы кремния с металлическими наночастицами на поверхности можно использовать как эффективные подложки для детектирования эффекта усиленного поверхностью рамановского рассеяния (SERS-эффект) от органических молекул. Обнаружено, что после первого этапа обработки кремниевые подложки демонстрировали существенный SERS-эффект от тестовых молекул родамина вплоть до концентраций родамина $\sim 5 \cdot 10^{-10} \mathrm{~g} / 1\left(10^{-12} \mathrm{M}\right)$.

Второй этап получения наноструктурированной поверхности служит для проведения селективного травления. На этом этапе применялась обработка водным раствором плавиковой кислоты и перекиси водорода для осуществления инициированного металлическими кластерами селективного травления кремния. Применялся водный раствор $\mathrm{HF}$ с низкой $(2.5 \mathrm{M})$ и высокой $(5 \mathrm{M})$ концентрацией, куда добавлялось соответственно 8 и 10 vol. $\% \mathrm{H}_{2} \mathrm{O}_{2}$.

На рис. 2 показана морфология поверхности и поперечный скол (на вставке) кремния $p$-типа проводимости после проведения двух этапов обработки. Видно, что подложка покрыта колоннами с поперечными размерами 


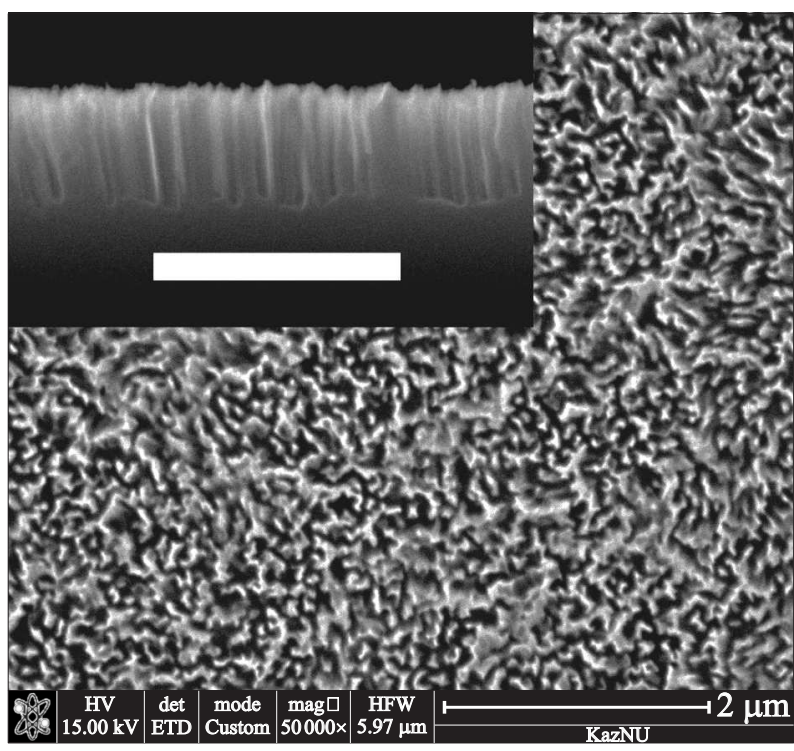

Рис. 2. SЕМ-снимок поверхности и бокового скола образца кремния, прошедшего двухэтапную обработку, время первого этапа $20 \mathrm{~s}$, концентрация $\mathrm{AgNO}_{3} 4 \mathrm{mmol} / \mathrm{l}$, длительность второго этапа травления в $\mathrm{H}_{2} \mathrm{O}_{2}+\mathrm{HF}+\mathrm{H}_{2} \mathrm{O}$ составляло $2 \mathrm{~min}$. На вставке к рисунку длина масштабного отрезка $1 \mu \mathrm{m}$.

около $50-100 \mathrm{~nm}$. Глубина структурированного слоя составляет около $300 \mathrm{~nm}$.

На рис. 3, $a$ показана зависимость средней толщины слоя наночастиц серебра (кривая 1) после первого этапа обработки в течение $20 \mathrm{~s}$ в зависимости от концентрации нитрата серебра. При концентрации $\mathrm{AgNO}_{3} 8 \mathrm{mmol} / 1$ достигается минимальный средний размер наночастиц. Можно отметить, что размер частиц варьируется незначительно при изменении концентрации $\mathrm{AgNO}_{3}$ в пределах $4-8 \mathrm{mmol} / \mathrm{l}$. Только при увеличении концентрации $\mathrm{AgNO}_{3}$ до $10 \mathrm{mmol} / \mathrm{l}$ и выше размер частиц начинает быстро расти.

На рис. 3, $a$ также показана зависимость толщины структурированного слоя после второго этапа обработки (кривая 2) в течение $60 \mathrm{~s}$ в зависимости от концентрации нитрата серебра в растворе на первом этапе обработки. Толщина структурированного слоя, получаемого после второго этапа обработки, слабо меняется при фиксированном времени второго этапа до концентрации $\mathrm{AgNO}_{3}$ $8 \mathrm{mmol} / 1$. При концентрации $\mathrm{AgNO}_{3}$ выше $10 \mathrm{mmol} / 1$ изза формирования крупных частиц серебра скорость травления на втором этапе резко растет, поэтому поверхностное сопротивление образца становится высоким и начинает сильно зависеть от параметров двухэтапного процесса.

Скорость роста структурированного слоя при высокой концентрации HF совпадает с данными, приведенными в [9], а при низкой концентрации примерно в $3-5$ раз меньше при малых временах травления. Глубина структурированного слоя линейно зависит от длительности второго этапа до $\sim 100 \mathrm{~s}$ (рис. $3, b$ ), после чего из-за ис- тощения травителя наступает существенное замедление скорости травления. На рис. $3, b$ показаны зависимости толщины структурированного слоя в кремнии как $p$-типа (кривая 1), так и $n$-типа проводимости (кривая 2) от длительности второго этапа обработки при следующих параметрах обработки на первом этапе: концентрация $\mathrm{AgNO}_{3}$ в растворе $4 \mathrm{mmol} / 1$, длительность $20 \mathrm{~s}$. Аналогичные зависимости глубины структурированного слоя от времени травления на втором этапе были получены и при других режимах первого этапа обработки. Слабая зависимость глубины структурированного слоя от длительности второго этапа обработки облегчает воспроизводимое получение образцов с низким поверхностным сопротивлением и низким коэффициентом отражения.

Из сравнения скорости травления кремния с удельным сопротивлением 5-15 $\Omega \cdot \mathrm{cm} p$-типа и $n$-типа при использовании одинаковых условий обработки видно, что
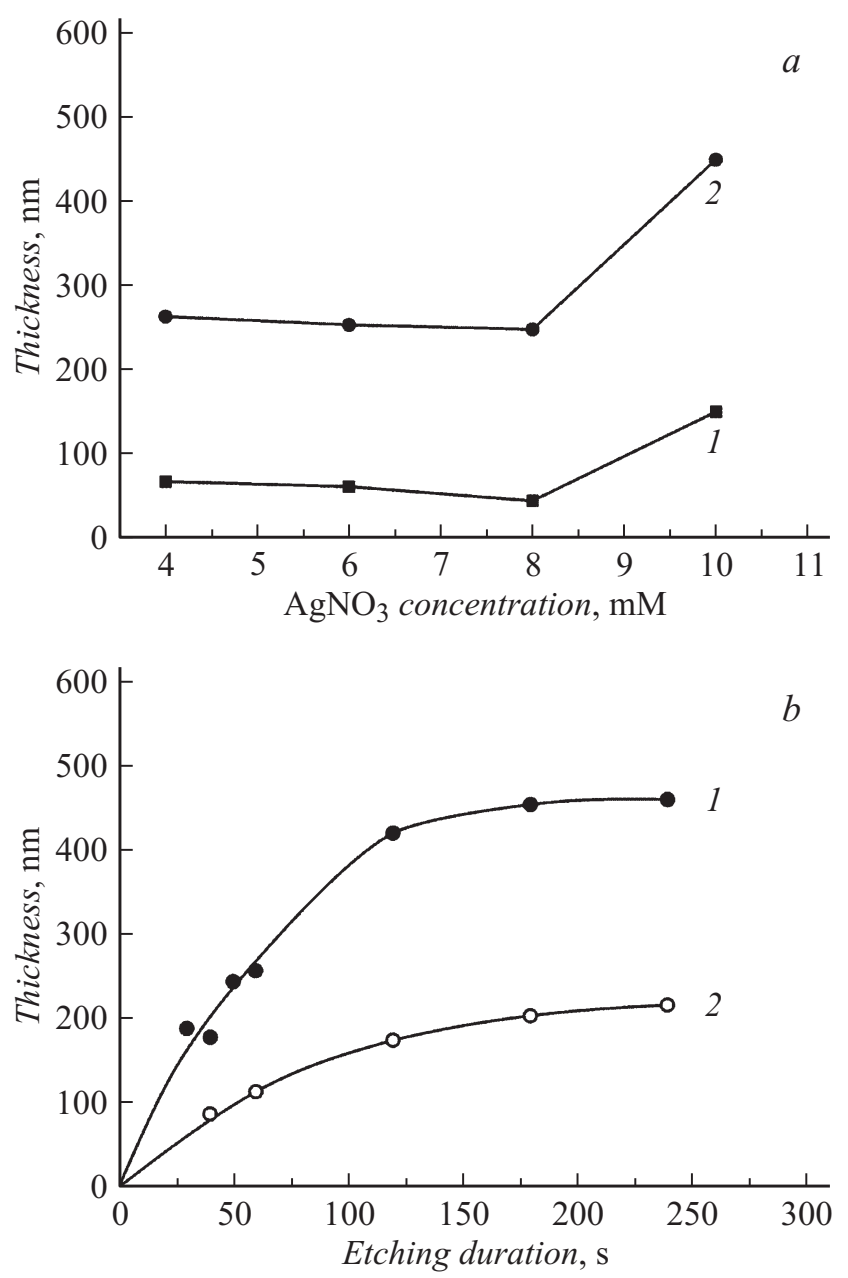

Рис. 3. $a-$ зависимости средней толщины слоя наночастиц после первого этапа обработки в течение $20 \mathrm{~s}$ (1) и толщины структурированного слоя после второго этапа обработки в течение $60 \mathrm{~s}(2)$ от концентрации $\mathrm{AgNO}_{3}$ в растворе на первом этапе обработки; $b-$ зависимость толщины структурированного слоя в кремнии $p$-типа (1) и $n$-типа (2) от длительности второго этапа обработки. 


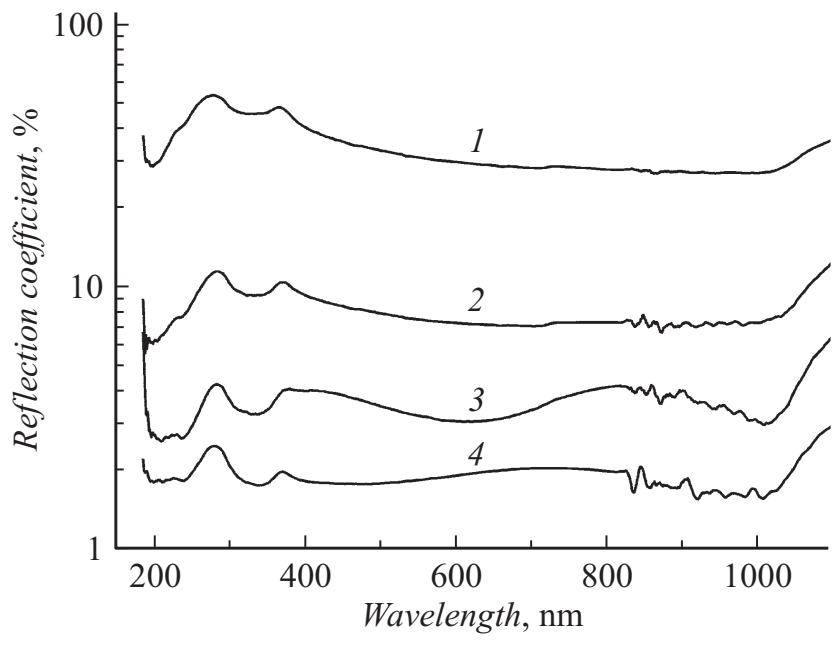

Рис. 4. Спектры оптического отражения образцов: исходная пластина кремния (1) и после селективного травления при длительности второго этапа 40 (2), 50 (3) и $60 \mathrm{~s}(4)$.

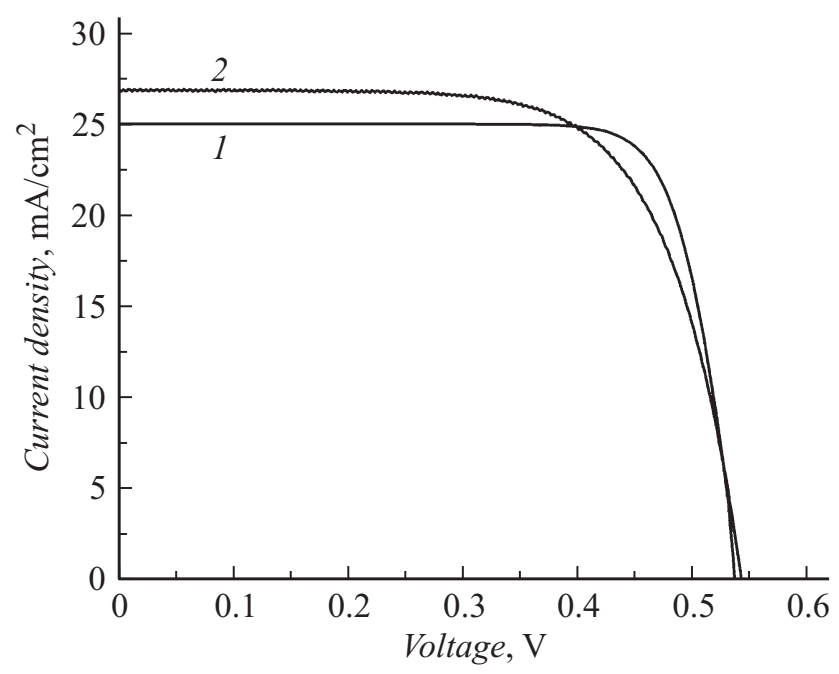

Рис. 5. Световые вольт-амперные характеристики контрольного СЭ (1) с эффективностью $10.5 \%$ и текстурированного СЭ (2) с эффективностью $10.7 \%$.

кремний $p$-типа травится примерно в два раза быстрее, чем кремний $n$-типа (рис. $3, b$ ).

Кремниевые поверхности, полученные после второго этапа обработки, имеют низкий коэффициент оптического отражения (рис. 4). Спектры оптического отражения образцов в диапазоне 200-1000 nm демонстрируют значительное падение коэффициента отражения с $~ 30$ до $\sim 2-3 \%$ в широком диапазоне длин волн. Минимальный коэффициент отражения достигался при концентрации раствора на первом этапе обработки $8 \mathrm{mmol} / \mathrm{l}$ $\mathrm{AgNO}_{3}$, длительности первого этапа $20 \mathrm{~s}$ и второго этапа $60-120 \mathrm{~s}$.

Чтобы продемонстрировать пригодность полученного кремния с низким коэффициентом отражения для создания СЭ, из пластин кремния были изготовлены образцы СЭ методом быстрой диффузии из поверхностного источника. Из-за более высокого последовательного сопротивления солнечных элементов на основе текстурированного кремния их фактор заполнения был в среднем ниже, чем у контрольного образца (рис. 5), однако благодаря более высокому фототоку, они имели эффективность выше, чем контрольный элемент.

\section{Заключение}

Методом селективного химического травления, инициированного металлическими нанокластерами, получены наноструктурированные поверхности кремниевых пластин, имеющие коэффициент отражения 2-4\% в видимом диапазоне. На кремниевых подложках, покрытых нанокластерами серебра, SERS-эффект наблюдался до концентраций тестового вещества $\sim 10^{-12} \mathrm{M}$. Определены параметры двухстадийного процесса, которые обеспечивают достижение низкого поверхностного сопротивления и низкого коэффициента отражения света в видимой области. При этом глубина структурированного слоя слабо зависит от вариаций параметров процесса обработки, что облегчает получение образцов с одинаковыми характеристиками. В кремнии $p$-типа скорость образования текстурированного слоя примерно в два раза выше, чем в кремнии $n$-типа при одинаковых условиях проведения процесса травления.

\section{Список литературы}

[1] Liu X., Coxon P.R., Peters M. et al. // Energy Environ. Sci. 2014. Vol. 7. P. 3223-3263.

[2] Wang H.P., Lin T.Y., Hsu C.W. et al. // ACS Nano. 2013. Vol. 7. N 10. P. 9325-9335.

[3] Savin H., Repo P., Gastrow G. et al. // Nature Nanotech. 2015. Vol. 10. P. 624-628.

[4] Creazzo T., Redding B., Marchena E. et al. // Opt. Express. 2010. Vol. 18. N 11. P. 10924-10930.

[5] Ivanova E.P., Hasan J. et al. // Nat Commun. 2013. Vol. 4. P. 2838.

[6] Deng Y.L., Juang Y.J. // Biosens. Bioelectron. 2014. Vol. 53. P. 37-42.

[7] Peng K., Wu Y., Fang H. et al. // Angew. Chem. Int. Edit. 2005. Vol. 44. P. 2797-2802.

[8] Peng K.Q., Hu J.J., Yan Y.J. et al. // Adv. Funct. Mater. 2006. Vol. 16. P. 387-394.

[9] Gonchar K.A., Osminkina L.A., Galkin R.A., Gongalsky M.B., Marshov V.S., Timoshenko V.Yu., Kulmas M.N., Solovyev V.V., Kudryavtsev A.A., Sivakov V.A. // J. Nanoelectron. Opt. 2012. Vol. 7. N 6. P. 602-606. 